University of Windsor

Scholarship at UWindsor

\title{
Effects of therapeutic touch on biochemical and mood indicators in women
}

Kathryn Lafreniere

University of Windsor

B. Mutus

S. Cameron

M. Tannous

Maria Gianotti

See next page for additional authors

Follow this and additional works at: https://scholar.uwindsor.ca/psychologypub

Part of the Psychology Commons

\section{Recommended Citation}

Lafreniere, Kathryn; Mutus, B.; Cameron, S.; Tannous, M.; Gianotti, Maria; Abu-Zahra, Hakim; and Laukannen, Ethan. (1999). Effects of therapeutic touch on biochemical and mood indicators in women. Journal of Alternative and Complementary Medicine, 5 (4), 367-370.

https://scholar.uwindsor.ca/psychologypub/2

This Article is brought to you for free and open access by the Department of Psychology at Scholarship at UWindsor. It has been accepted for inclusion in Psychology Publications by an authorized administrator of Scholarship at UWindsor. For more information, please contact scholarship@uwindsor.ca. 


\section{Authors}

Kathryn Lafreniere, B. Mutus, S. Cameron, M. Tannous, Maria Gianotti, Hakim Abu-Zahra, and Ethan Laukannen 


\title{
Effects of Therapeutic Touch on Biochemical and Mood Indicators in Women
}

\author{
KATHRYN D. LAFRENIERE, Ph.D. ${ }^{1}$ BULENT MUTUS, Ph.D., ${ }^{1}$ SHEILA CAMERON, Ed.D., ${ }^{1}$ \\ MARIE TANNOUS, Ph.D. ${ }^{1}$ MARIA GIANNOTTI, B.Ed., ${ }^{2}$ HAKAM ABU-ZAHRA, M.B., ${ }^{2}$ \\ and ETHAN LAUKKANEN, M.D. ${ }^{2}$
}

\begin{abstract}
Previous research has shown therapeutic touch (TT) to be effective in reducing anxiety and discomfort and promoting relaxation. The present investigation experimentally evaluated the effects of TT on biochemical indicators and moods in a sample of $\mathbf{4 1}$ healthy female volunteers. Participants were randomly assigned to either an experimental group who received TT or to a control group who did not receive TT. Pretest and posttest urine samples were collected, and personality and mood inventories were administered across three consecutive monthly sessions. Results indicated that mood disturbance in the experimental group decreased significantly over the course of the three sessions, while the control group increased in mood disturbance over time. Specifically, experimental group participants showed significant reductions in tension, confusion, and anxiety and a significant increase in vigor across sessions. Analyses of the biochemical data indicated that TT produced a significant decrease in levels of nitric oxide in the experimental group by the third TT session. The results of the present investigation have important implications for reducing symptom distress in cancer patients undergoing chemotherapy.
\end{abstract}

\section{INTRODUCTION}

T The present investigation was conducted as an open pilot study for subsequent research investigating the effects of therapeutic touch (TT) on breast cancer patients undergoing chemotherapy. Chemotherapy is frequently accompanied by a number of distressing symptoms, including fatigue, nausea, vomiting, and loss of appetite, as well as mood disturbance in the form of anxiety and depression (Carey and Burish, 1988). A number of approaches have been used to address these as- pects of patient distress. One technique that has been successfully used in pain and symptom management is TT. TT is an intervention that involves using the hands to facilitate a healing process by assisting patients to achieve balance in their energy fields (Wright, 1994). Research investigations have demonstrated the efficacy of TT in reducing anxiety in hospitalized cardiovascular patients (Heidt, 1981; Quinn, 1981), reducing arousal in premature infants (Fedoruk, 1983), and decreasing tension headache pain (Keller and Bzdek, 1986). One investigation showed that breast cancer patients who

\footnotetext{
${ }^{1}$ University of Windsor, Windsor, Ontario, Canada.

${ }^{2}$ Windsor Regional Cancer Centre, Windsor, Ontario, Canada.
} 
were familiar with TT expressed the most positive attitudes toward it, and that many women were receptive to it as a possible intervention (Thomas-Beckett, 1991).

Although there is a growing body of research to demonstrate the increasing use and acceptance of TT by patients with a variety of health problems, few studies have used experimental methods to examine its efficacy, and research that investigates the biochemical effects of TT is particularly lacking. In this study, attempts were made to quantify the effects of TT by examining levels of several hormones and neurotransmitters that are currently implicated in the regulation of vomiting. Previous research has reported an indirect relationship between chemotherapy-induced emesis and urinary corticosteroid levels (Fredrikson et al., 1992). Nitric oxide (NO) is a recent addition to the list of neurotransmitters that are thought to regulate emesis. Elevated NO levels have been related to nausea and vomiting in postangiography headache (Ramadan et al., 1995).

The primary objective of the present investigation was to evaluate the effects of TT on hormonal and neurotransmitter indicators, in addition to indicators of mood and anxiety in a sample of nonpatients. The hormonal and neurotransmitter indicators used in this study were cortisol, total catecholamine (dopamine), and NO (detected as nitrite in the urine). It was hypothesized that participants randomly assigned to the TT group would experience a reduction in mood disturbance, anxiety, and fatigue as a result of the TT, in comparison with a control group who received no TT. It was further expected that levels of cortisol, dopamine, and NO would decrease as a function of TT.

\section{METHODS}

\section{Participants}

The sample comprised 41 healthy female volunteers who ranged in age from 30 to 64 years of age, with a mean age of 44.24 years. Participants were randomly assigned to an experimental group that received TT $(n=22)$, or to a control group that completed questionnaire measures but received no TT $(n=19)$.

\section{Questionnaire measures}

Participants in both groups completed the same questionnaire measures. At session 1, participants completed a questionnaire that included the Profile of Mood States (POMS; McNair et al., 1971), and the State-Trait Anxiety Inventory (STAI; Spielberger et al., 1970).

\section{Procedure}

Experimental group participants were taken to a laboratory room and instructed to remove their shoes and lie on a hospital bed. Soft music was played on a portable tape player while TT was administered by a trained, experienced energy practitioner.

The practitioner followed the following TT steps:

1. Centering: becoming still and reaching a focused state;

2. Assessment: moving hands over the body to identify imbalances or obstructions in the energy field;

3. Unruffling: moving the hands to facilitate the free flow of energy through the body;

4. Directing and modulating energy: energy is directed to areas of the body that are detected to be blocked or congested in order to restore balance;

5. Stopping: when energy balance has been restored (Krieger, 1979).

The participant was then allowed to rest for a period of 5 to 10 minutes. After the resting period, the participant was accompanied to a nearby testing room where she filled out the questionnaires. Participants in the control group went directly to the testing room to fill out the questionnaires. After the data collection was completed, control group participants were contacted and offered a free TT demonstration session. A majority of participants in the control group attended these demonstration sessions.

\section{RESULTS AND DISCUSSION}

Overall, the primary hypotheses were supported by the results of the present study. Par- 
ticipants in the TT group showed a significantly greater reduction in mood disturbance across sessions, relative to the control group $[F(2$, $32)=6.06, p<0.01]$. This interaction is depicted in Figure 1, and illustrates a marked decrease in mood disturbance by Session 3 for the TT group only. Specifically, TT was shown to reduce self-reported tension $[F(2,66)=3.19$, $p<0.05]$, and was therefore effective as a relaxation technique. TT group participants also reported significantly less confusion $[F(2$, $66)=6.26, p<0.01]$ and increased vigor $[F(2$, $66)=4.48, p<0.05]$ across the three sessions. In addition, anxiety declined significantly in the TT group, but not in the control group, $[F$ $(2,32)=6.53, p<0.01]$. Taken together, these findings suggest that the administration of TT across three monthly sessions had beneficial consequences for participants in the experimental group. Despite the fact that women who were randomly assigned to the TT group rated their own health more negatively (possibly due to the presence of more health problems), they showed higher levels of energy and less anxiety, tension, and confusion than control group participants after their exposure to TT.

Analyses of the biochemical data indicated that TT produced a significant decrease in levels of NO in the experimental group by the third TT session, $[F(1,35)=4.18, p<0.05]$. This has particular relevance for cancer patients undergoing chemotherapy as elevation of NO is related to postangiography headache, vomiting and nausea (Ramadan et

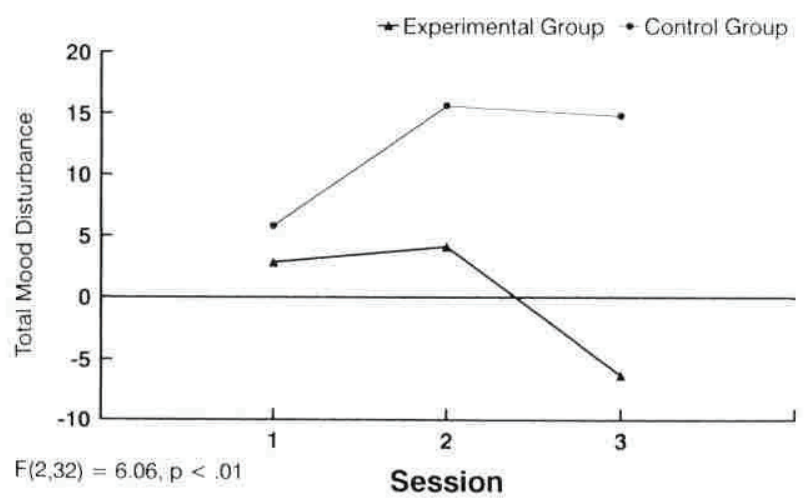

FIG. 1. Profile of Mood States (POMS) mood disturbance by group and session. al., 1995). No significant effects emerged for cortisol or catecholamines across the three sessions.

Findings across the three sessions revealed that group differences emerged most strongly in the third experimental session, both with respect to reduction in $\mathrm{NO}$ and positive changes in mood. The present results therefore suggest that the beneficial effects of TT were cumulative.

A frequent criticism of research findings in support of alternative therapies is that they might actually reflect placebo effects, rather than demonstrating genuine effects of the specific therapeutic agent. Typical remedies for placebo effects involve the use of blind and double-blind research designs, but these are precluded in investigations of alternative therapies in which the intentionality of the therapist and of the recipient are integral components of the treatment. Nonetheless, the design and results of the present investigation suggest that more than mere placebo effects were operative. The inclusion of biochemical measures, in addition to self-report inventories, makes it less likely that participants' expectations about the efficacy of treatments would account for the different outcomes observed between groups. The assignment of participants to groups through a random procedure, rather than through self-selection, militates against the possibility that members of the treated group are more likely to be "believers," who have a strong vested interest in supporting the efficacy of the treatment.

The inability to use a blind experimental design is a clear limitation of the present research. Further limitations in our pilot study related to procedural differences between the experimental and control conditions. In the experimental condition, administration of TT was accompanied by soft music, with participants reclining, to approximate conditions in the clinical setting. Control participants came to the laboratory and filled out measures in the presence of research assistants, but were not exposed to the TT practitioner, and were not given the opportunity to recline and listen to soft music. It is therefore arguable that our observed between-group differences were influenced to some degree by this lack of standard- 
ization across conditions. Our future research in the clinical setting will ensure that such background variables are consistent across experimental conditions.

Despite these limitations, the positive findings of reductions in mood disturbance and decreased levels of NO across experimental sessions observed in this pilot study do suggest that further research in this area is warranted. Further studies that examine the effects of TT on breast cancer patients who experience treatment-related distress will provide valuable information on the effectiveness of an alternative therapy that may have the potential to improve the quality of life of women who are undergoing chemotherapy.

\section{ACKNOWLEDGMENTS}

The authors gratefully acknowledge the contributions of Tracy Little, Jody Wolfe, and Jodi Kessel, who provided research assistance.

This study was supported by research funding from the Windsor Regional Cancer Centre.

\section{REFERENCES}

Carey MP, Burish, TG. Etiology and treatment of the psychological side effects associated with cancer chemotherapy: A critical review and discussion. Psychol Bull 1988;104:307-325.

Fedoruk RB. Transfer of the relaxation response: Therapeutic Touch B as a method for reduction of stress in premature neonates [dissertation]. University of Maryland, 1983.
Fredrikson M, Hursti T, Furst CJ, Steineck G, Borjesson S, Wikblom M, Peterson C. Nausea in cancer chemotherapy is inversely related to urinary cortisol excretion. $\mathrm{Br}$ J Cancer 1992;65:779-780.

Heidt P. Effect of therapeutic touch on anxiety level of hospitalized patients. Nurs Res 1981;30:32-37.

Keller E, Bzdek VM. Effects of therapeutic touch on tension headache pain. Nurs Res 1986;35:101-105.

Krieger D. The Therapeutic Touch: How to Use Your Hands to Help or to Heal. Englewood Cliffs, NJ: Prentice-Hall, 1979.

McNair DM, Lorr M, Droppleman, LF. The Profile of Mood States. San Diego: Educational and Industrial Testing Service, 1971.

Quinn J. An investigation of the effects of Therapeutic Touch done without physical contact on state anxiety of hospitalized cardiovascular patients [dissertation]. New York University, 1981.

Ramadan NM, Gilkey SJ, Mitchell M, Sawaya KL, Mitsias P. Postangiography headache. Headache 1995;35:21-24.

Spielberger CD, Gorsuch RL, Lushene RE. STAI Manual for the State-Trait Inventory. Palo Alto, CA: Consulting Psychologists Press, 1970.

Thomas-Beckett JG. Attitudes toward therapeutic touch: A pilot study of women with breast cancer [masters thesis]. Michigan State University, 1991.

Wright S. Therapeutic Touch and Healing Touch: What is the difference? Cooperative Connection: Newsletter of the Nurse Healers-Professional Associates 1994; 15:1-3.

Address reprint requests to: Kathryn D. Lafreniere, Ph.D.

University of Windsor

Psychology Department

401 Sunset Avenue

Windsor, Ontario N9B 3P4

Canada

E-mail: lafren1@uwindsor.ca 